\title{
SIKAP DAN KEPUASAN KONSUMEN RUMAH MAKAN “XXX” LAMONGAN DI BANDAR LAMPUNG
}

\author{
(Attitude and Satisfaction of Consumers of "XXX” Lamongan Restaurant in Bandar Lampung)
}

Rinty Azaria, Sudarma Widjaya dan Maya Riantini

Jurusan Agribisnis, Fakultas Pertanian, Universitas Lampung, Jl. Prof. Dr. Soemantri Brojonegoro No. 1

Bandar Lampung 35145,e-mail : maya.riantini@fp.unila.ac.id

\begin{abstract}
This study aims to explore the consumers' attitudes and satisfaction toward restaurant. This research is conducted at "XXX" Lamongan Restaurant in Bandar Lampung. Data collection was carried out in January-February 2019 by the case study method employing the number of respondents of 60 people who were selected by nonprobability sampling method. The data were analyzed using Multiatribut Fishbein Model, Customer Satisfaction Index and Importance Performance Analysis. The results of this research showed that food taste has the highest score of consumers attitude toward restaurant. The satisfaction level of the restaurant has the value of $83.73 \%$, included to the very satisfied category. The restaurant has been implementing the product attributes that were suitable with consumers' wishes.
\end{abstract}

Key words : consumer, restaurant, satisfaction

\section{PENDAHULUAN}

Usaha Mikro Kecil dan Menengah (UMKM) merupakan basis ekonomi kerakyatan yang sangat penting perannya dalam pembangunan ekonomi nasional, karena dapat memperluas lapangan kerja dan memberikan pelayanan ekonomi secara luas kepada masyarakat. Usaha Mikro Kecil dan Menengah (UMKM) mampu mengatasi permasalahan pengangguran yang kerap terjadi.

Salah satu unit usaha yang termasuk dalam UMKM adalah rumah makan. Menurut Dinas Pariwisata Kota Bandar Lampung (2017), jumlah rumah makan di Bandar Lampung sebanyak 192 unit dan dibagi menjadi 2 jenis rumah makan, yaitu rumah makan nasional dan rumah makan internasional. Rumah makan nasional di Bandar Lampung tercatat sebanyak 174 unit dan rumah makan internasional sebanyak 18 unit. Berdasarkan data tersebut menunjukkan bahwa rumah makan nasional lebih banyak dibandingkan rumah makan internasional.

Salah satu jenis rumah makan nasional yaitu rumah makan yang menjual sejenis pecel lele, Rumah Makan "XXX" Lamongan. Rumah makan ini merupakan termasuk usaha kecil yang memiliki omset antara 300,00 juta - 2,50 milyar per tahun. Rumah Makan "XXX" Lamongan berkembang cukup pesat yang dapat dilihat dari jumlah pengunjung yang datang. Rumah Makan "XXX" Lamongan setiap hari memiliki jumlah pengunjung yang berbeda. Sampai saat ini, Rumah Makan "XXX" Lamongan mampu bersaing dengan rumah makan sejenisnya, baik rumah makan yang sudah lama maupun baru. Lokasi rumah makan relatif strategis (dekat perumahan dan perkantoran), sehingga Rumah Makan "XXX" Lamongan selalu ramai dengan pengunjung. Pengunjung yang datang ke rumah makan ini meliputi pegawai kantor serta penghuni perumahan yang berada di sekitar rumah makan.

Pengunjung Rumah Makan "XXX" Lamongan sebagai konsumen memiliki karakteristik yang berbeda-beda dalam hal usia, pendidikan, pekerjaan, pendapatan, dan domisili konsumen tersebut. Perbedaan yang dimiliki masing-masing konsumen menyebabkan perbedaan dalam menentukan penilaian terhadap produk tersebut.

Menurut Kotler (2005), sikap adalah perilaku yang menunjukkan apa yang disukai maupun tidak disukai oleh konsumen, karena setiap konsumen memiliki perbedaan sikap serta pengetahuan yang dimiliki. Kepuasan adalah perasaan senang atau kecewa dari seseorang yang muncul setelah membandingkan antara kinerja (hasil) produk yang dipikirkan terhadap kinerja yang diharapkan. Apabila kinerja berada di bawah harapan, maka konsumen tidak puas, sedangkan jika kinerja memenuhi harapan, maka konsumen puas. Jika kinerja melebihi harapan, maka konsumen amat puas atau amat senang. Untuk itu diperlukan penilaian terhadap rumah makan tersebut apakah 
konsumen dapat merasa puas atau tidak. Berdasarkan uraian tersebut, maka tujuan penelitian ini yaitu untuk mengetahui sikap dan tingkat kepuasan konsumen Rumah Makan "XXX" Lamongan.

\section{METODE PENELITIAN}

Penelitian ini menggunakan metode studi kasus. Pengumpulan data dilakukan pada bulan Januari sampai Febuari 2019. Penelitian dilaksanakan di Rumah Makan "XXX" Lamongan yang terletak di Jalan Arief Rahman Hakim, Way Halim Bandar Lampung. Pemilihan lokasi dilakukan secara sengaja (purposive) dengan pertimbangan rumah makan tersebut sudah lama berdiri dan berkembang cukup pesat di Kota Bandar Lampung.

Penentuan responden menggunakan metode nonprobability sampling yaitu accidental sampling. Metode accidental sampling merupakan teknik pengambilan sampel secara kebetulan kepada konsumen yang sedang makan di rumah makan tersebut. Jumlah sampel pada penelitian sebanyak 60 responden. Jadi pemilihan responden didasarkan pada pertimbangan konsumen yang sudah pernah melakukan pembelian di Rumah Makan "XXX" Lamongan dan bersedia untuk diwawancarai serta mengisi sendiri kuesioner yang telah disiapkan. Responden diwawancarai pada saat makan siang, makan sore dan makan malam.

Sebelum melakukan analisis sikap dan kepuasan konsumen terhadap Rumah Makan "XXX" Lamongan, terlebih dahulu dilakukan uji validitas dan reliabilitas. Uji validitas menggambarkan tentang keabsahan dari alat ukur apakah pertanyaan-pertanyaan sudah tepat untuk mengukur apa yang ingin diukur. Nilai validitas dapat dikatakan baik, jika nilai Corrected Item dari Total Correlation bernilai di atas 0,20 (Sufren dan Natanael 2013). Uji reliabilitas merupakan indeks yang menunjukkan sejauh mana suatu alat pengukur dapat dipercaya atau dapat diandalkan. Pengujian reliabilitas menggunakan uji statistik Cronbach's Alpha. Suatu instrumen dikatakan reliable, jika nilai Cronbach's Alpha lebih besar dari lebih besar dari 0,70 (Ghozali 2009).

Hasil uji validitas dan reliabilitas kuesioner tingkat kepentingan dan tingkat kepercayaan, konsumen Rumah Makan "XXX" Lamongan sudah valid dan reliabel. Hasil uji validitas kuesioner tingkat kepentingan, tingkat kepercayaan, uji validitas dan reliabilitas atribut-atribut dalam kuesioner dilakukan terhadap 30 responden pertama sebagai sampel. Pada hasil uji dinyatakan bahwa semua atribut pada penelitian ini adalah valid dan reliabel. Nilai Corrected Item-Total Correlation menunjukkan angka lebih dari 0,20 yang artinya pertanyaan yang diajukan pada kuesioner adalah valid. Jika dilihat dari nilai Cronbach's Alpha tingkat kepentingan rumah makan sebesar 0,81 dan Cronbach's Alpha tingkat kepercayaan rumah makan sebesar 0,88 maka semua pertanyaan yang diajukan di dalam kuesioner juga dinyatakan reliabel, karena nilainya lebih dari 0,70. Hal ini berarti pengukuran dengan pengumpulan data yang dilakukan dapat memberikan hasil yang konsisten bila dilakukan pengukuran kembali terhadap subjek yang sama.

Model sikap Multiatribut Fishbein menggambarkan rancangan yang berharga untuk memeriksa hubungan antara pengetahuan produk yang dimiliki konsumen dan sikap terhadap produk dengan ciri atau atribut produk. Analisis Multiatribut Fishbein juga merupakan sumber informasi yang berguna bagi perencanaan dan tindakan pasar. Model Multiatribut Fishbein merupakan evaluasi konsumen terhadap objek berdasarkan kepada evaluasinya terhadap banyak atribut yang dimiliki oleh objek tersebut. Analisis tersebut juga digunakan dalam penelitian yang dilakukan oleh Doloksaribu, Indriani, dan Kalsum (2016) untuk menentukan sikap konsumen. Model Multiatribut Fishbein dapat dirumuskan sebagai berikut:

$$
\text { Ao }=\sum_{\mathrm{i}=1}^{\mathrm{n}} \text { ei.bi. }
$$

Keterangan :

Ao $=$ skor sikap terhadap produk

bi $=$ kekuatan kepercayaan terhadap atribut $\mathrm{i}$

ei $=$ evaluasi mengenai atribut ke-i

$\mathrm{n}=$ jumlah atribut

$\mathrm{i}=$ atribut ke-i $(1,2,3, \ldots, \mathrm{n})$

Penilaian dengan analisis Fishbein ini diambil dari perhitungan nilai rata-rata masing-masing atribut untuk seluruh responden, lalu diformulasikan ke dalam metode Fishbein dan hasilnya berupa nilai sikap Fishbein untuk setiap produk atau merek "X" (Ao) yang ditampilkan dalam suatu tabel (Engel et al 1995).

Untuk mengetahui tingkat kepuasan konsumen digunakan analisis Customer Satisfaction Index (CSI) dan Importance Performance Analysis (IPA). Analisis CSI digunakan untuk mengukur 
indeks kepuasan konsumen secara keseluruhan dari tingkat kepentingan dan tingkat kinerja yang dapat mempengaruhi kepuasan pelanggan (Supranto 2006). Pengukuran CSI terdiri dari empat tahap yaitu:

1. Menghitung Weighting Factor (WF), yaitu mengubah nilai rata-rata kepentingan menjadi angka persentase dari total rata-rata tingkat kepentingan seluruh atribut yang diuji.

2. Menghitung Weighted Score (WS), yaitu menilai perkalian antara nilai rata-rata tingkat kinerja masing-masing atribut dengan Weighting Factor (WF) masing-masing atribut.

3. Menghitung Weighted Total (WT), yaitu menjumlahkan WS dari semua atribut.

4. Menghitung Satisfaction Index, yaitu WT dibagi skala maksimum yang digunakan, dalam penelitian ini skala maksimum yang digunakan adalah 5 kemudian dikalikan 100,00\%.

Rentang skala dan interpretasi analisis Customer Satisfaction Index (CSI) keseluruhan (Supranto 2006) yaitu :

$0,00-0,20=$ Sangat tidak puas

$0,21-0,40=$ Tidak puas

$0,41-0,60=$ Cukup puas

$0,61-0,80=$ Puas

$0,81-1,00=$ Sangat puas

Rentang skala CSI sesuai dengan penelitian yang dilakukan Sulfiana, Murniati, dan Indriani (2018) yang menggunakan Customer Satisfaction Index (CSI) dalam menentukan kepuasan konsumen terhadap paket menu lele terbang di Rumah Makan Sambal Lalap Bandar Lampung.

Analisis Importance Performance analysis (IPA) digunakan untuk menggambarkan kinerja (performance) dibandingkan dengan tingkat kepentingan (importance) yang dipersepsikan oleh konsumen dalam bentuk grafik. Hasil analisis IPA digambarkan pada diagram kartesius yang terdiri dari empat kuadran (Supranto 2006).

1. Kuadran I menunjukkan atribut yang mempengaruhi tingkat kepuasan pelanggan, namun belum dilaksanakan dengan baik.

2. Kuadran II menunjukkan unsur-unsur jasa pokok yang telah berhasil dilaksanakan oleh pihak perusahaan dan mempengaruhi kepuasan.

3. Kuadran III menunjukkan faktor yang kurang penting pengaruhnya bagi tingkat kepuasan pelanggan dan pelaksanaannya biasa saja.

4. Kuadran IV menunjukkan faktor yang kurang penting mempengaruhi kepuasan pelanggan, tetapi pelaksanaan kinerjanya berlebihan.

\section{HASIL DAN PEMBAHASAN}

\section{Karakteristik Konsumen}

Konsumen Rumah Makan "XXX" Lamongan memiliki karakteristik yang berbeda-beda dalam hal usia, pendidikan, pekerjaan, pendapatan, dan domisili konsumen tersebut. Sebagian besar konsumen berada pada usia 21-30 tahun. Ini menunjukkan bahwa sebagian besar pengunjung berusia muda dan masih kuliah atau bekerja. Pendapatan konsumen perbulan terbanyak sebesar $>$ Rp3.500.000 dengan persentase sebesar 48 persen per bulan. Sebanyak 34 konsumen menempuh jarak 0-5 km untuk mencapai ke lokasi Rumah Makan "XXX" Lamongan dari lokasi sebelumnya $(57,00$ persen) dan sisanya sebanyak 26 konsumen menempuh jarak 5-10 km $(43,00$ persen). Sebagian besar pekerjaan konsumen adalah karyawan swasta dengan jenjang pendidikan terakhir yaitu $\mathrm{S} 1$.

\section{Sikap Konsumen}

Sikap konsumen merupakan ungkapan perasaan seseorang terhadap Rumah Makan "XXX" Lamongan apakah disukai atau tidak. Atributatribut produk yang diidentifikasi pada penelitian ini adalah penampilan produk, harga, rasa, higienitas, variasi menu, keramahan pelayan, kecepatan transaksi, kebersihan toilet dan cuci tangan, ketanggapan dalam merespon keluhan konsumen, dan kemudahan dalam menjangkau lokasi tempat. Sikap responden yang dianalisis terdiri dari evaluasi tingkat kepentingan dan kepercayaan terhadap atribut Rumah Makan "XXX" Lamongan di Bandar Lampung.

Tabel 1. Skor sikap (Ao) terhadap atribut Rumah Makan "XXX" Lamongan Bandar Lampung

\begin{tabular}{|c|c|c|c|}
\hline \multirow[t]{2}{*}{ Atribut } & \multicolumn{3}{|c|}{ Evaluasi Skor } \\
\hline & & bi & ei.bi \\
\hline - Penampilan produk & 4,35 & 4,28 & 18,63 \\
\hline - Harga & 4,65 & 4,25 & 19,76 \\
\hline$-\mathrm{Ra}$ & 4,72 & 4,55 & 21,46 \\
\hline - Higienitas & 4,58 & 4,35 & 19,94 \\
\hline - Var & 4,12 & 4,05 & 16,67 \\
\hline - Ker & 4,27 & 4,12 & 17,56 \\
\hline$-\mathrm{Kec}$ & 4,32 & 3,93 & 16,98 \\
\hline$-\mathrm{Keb}$ & 4,63 & 4,28 & 19,85 \\
\hline $\begin{array}{l}\text { - Ketangkapan dalam merespon } \\
\text { keluhan konsumen }\end{array}$ & 4,23 & 3,95 & 16,72 \\
\hline $\begin{array}{l}\text { - Kemudahan dalam menjangkau } \\
\text { lokasi tempat }\end{array}$ & 4,37 & 4,03 & 17,61 \\
\hline Jumlah (Ao) & & & 185,19 \\
\hline
\end{tabular}


Berdasarkan Tabel 1, skor Multiatribut Fishbein terhadap sikap rumah makan didapatkan hasil sebesar 185,19. Atribut yang mendapat skor Ao tertinggi pada rumah makan adalah atribut rasa yaitu 21,46 dan skor sikap terendah pada rumah makan adalah variasi menu sebesar 16,67. Penelitan ini sejalan dengan penelitian Bangun, Indriani, dan Soelaiman (2016) dengan judul sikap dan kepuasan konsumen dalam mengonsumsi ayam penyet Hang Dihi menunjukkan bahwa atribut rasa memperoleh skor tertinggi.

\section{Customer Satisfaction Index (CSI)}

Analisis tingkat kepuasan konsumen diukur menggunakan Customer Satisfaction Index (Indeks Kepuasan Konsumen) dengan menilai tingkat kepentingan dan tingkat kinerja atribut produk. Indeks kepuasan konsumen adalah sebuah angka yang menyatakan seberapa besar tingkat kepuasan konsumen terhadap suatu produk. Pada Tabel 2, nilai Customer Satisfaction Index (CSI) rumah makan yang diperoleh adalah 83,73 persen. Berdasarkan hasil perhitungan penelitian, nilai CSI konsumen rumah makan berada pada rentang skala 81,00 persen sampai 100,00 persen, sehingga dapat disimpulkan bahwa indeks kepuasan konsumen rumah makan berada pada kriteria sangat puas.

Tabel 2. Perhitungan menggunakan metode Customer Satisfaction Index (CSI) Rumah Makan "XXX” Lamongan

\begin{tabular}{lcccc}
\hline \multicolumn{1}{c}{ Atribut } & $\begin{array}{c}\text { Atribut } \\
\text { Tingkat } \\
\text { Kepentingan } \\
\text { (Y) }\end{array}$ & WF & $\begin{array}{c}\text { Tingkat } \\
\text { Kinerja } \\
(\mathrm{X})\end{array}$ & WS \\
& 4,35 & 0,10 & 4,28 & 0,42 \\
\hline - Penampilan produk & 4,65 & 0,11 & 4,25 & 0,45 \\
- Harga & 4,72 & 0,11 & 4,55 & 0,49 \\
- Rasa & 4,58 & 0,10 & 4,35 & 0,45 \\
- Higienitas & 4,12 & 0,09 & 4,05 & 0,38 \\
- Variasi menu & 4,27 & 0,10 & 4,12 & 0,40 \\
- Keramahan & & & & \\
pelayan & 4,32 & 0,10 & 3,93 & 0,38 \\
- Kecepatan & & & & \\
transaksi & 4,63 & 0,10 & 4,28 & 0,45 \\
- Kebersihan toilet & & & & \\
$\quad$ dan cuci tangan & 4,23 & 0,10 & 3,95 & 0,38 \\
- Ketangkapan & & & & \\
dalam merespon & & & & \\
keluhan konsumen & 4,37 & 0,10 & 4,03 & 0,40 \\
- Kemudahan dalam & $4,33,73 \%$ \\
menjakau lokasi \\
tempat
\end{tabular}

Penelitian ini sejalan dengan penelitian Sitorus (2018) tentang sikap dan kepuasan konsumen terhadap pembelian sate di Kota Bandar Lampung menyatakan bahwa nilai Customer Satisfaction Index (CSI) terhadap pembelian sate di Kota Bandar Lampung konsumen berada pada kriteria sangat puas. Konsumen memberikan nilai kepuasan tertinggi pada atribut rasa dengan nilai 0,49 dan atribut variasi menu, kecepatan transaksi, dan ketangkapan dalam merespon keluhan konsumen mendapatkan nilai terendah sebesar 0,38. Rumah Makan "XXX" Lamongan dinilai baik oleh konsumen, serta memiliki kinerja yang baik, sehingga dapat memenuhi kepuasan konsumen.

\section{Importance Performance Analysis (IPA)}

Tingkat kepuasan konsumen dipengaruhi oleh atribut produk yang dianggap penting oleh konsumen dengan menggunakan metode Importance Performanfe Analysis (IPA), dapat diketahui bagaimana tingkat kepentingan dan kinerja setiap atribut yang mana yang akan menjadi prioritas untuk diperbaiki dan ditingkatkan oleh produsen dengan menggunakan Diagram Kartesius. Grafik diagram kartesius Importance Performance Analysis (IPA) dapat dilihat pada Gambar 1.

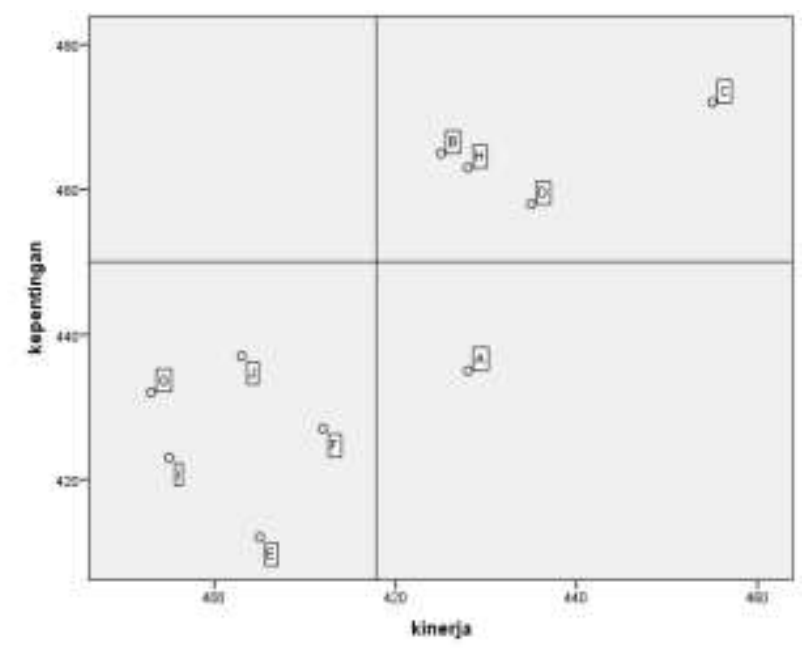

Gambar 1. Diagram kartesius rumah makan
Keterangan :
A. Penampilan Produk
B. Harga
C. Rasa
D. Higienitas
E. Variasi menu
F. Keramahan pelayan
G. Kecepatan transaks
H. Kebersihan toilet dan cuci tangan
I. Ketangkapan dalam merespon keluhan konsumen
J. Kemudahan dalam menjangkau lokasi 


\section{Kuadran I Prioritas Utama}

Kuadran I disebut prioritas utama, tetapi di Rumah Makan "XXX" Lamongan tidak terdapat atribut yang masuk ke dalam kuadran I, karena Rumah makan tersebut memiliki kinerja yang sesuai dengan apa yang diinginkan oleh konsumen.

\section{Kuadran II Pertahankan Prestasi}

Atribut yang termasuk dalam kuadran ini adalah rasa, harga, higienitas, dan kebersihan toilet dan cuci tangan. Atribut yang termasuk ke dalam kuadran II harus dipertahankan kinerjanya oleh pihak Rumah Makan "XXX" Lamongan, karena dianggap penting oleh konsumen. Penelitian ini sejalan dengan Sulfiana dkk (2018) yang meneliti tentang sikap dan kepuasan konsumen terhadap paket menu lele terbang di rumah makan sambal lalap Bandar Lampung yang mendapatkan bahwa atribut rasa berada pada kuadran II yang merupakan kuadran pertahankan prestasi.

Atribut rasa yaitu dengan memperhatikan kualitas bahan baku yang akan digunakan dan upaya cita rasa yang konsisten dan tidak berubah. Atribut harga juga perlu dipertahankan. Harga makanan dan minuman rumah makan tersebut dianggap sudah dapat memenuhi keinginan konsumen, karena harga yang diberikan pihak rumah makan relatif sama dengan rumah makan yang sejenis. Atribut ini perlu dipertahankan, agar konsumen tetep merasa puas dalam melakukan pembelian.

Atribut selanjutnya yang masuk ke dalam kuadran II adalah atribut higienitas. Upaya yang dilakukan oleh rumah makan yaitu dalam proses pengolahan makanan dan minuman, koki yang bertugas dipastikan sudah menggunakan perlengkapan yang mendukung, agar proses pengolahan makanan dan minuman terhindar dari kotoran dan tetap higienis. Atribut kebersihan toilet dan cuci tangan juga perlu dipertahankan. Upaya yang dilakukan oleh rumah makan untuk mempertahankan kebersihan toilet dan cuci tangan yaitu dengan selalu menjaga kebersihan tempat, agar terhindar dari kotoran. Kebersihan suatu tempat juga akan sangat mempengaruhi konsumen ketika ingin berkunjung pada rumah makan tersebut.

\section{Kuadran III Prioritas Rendah}

Atribut yang termasuk ke dalam kuadran ini adalah variasi menu, kemudahan dalam menjangkau lokasi tempat, keramahan pelayan, kecepatan transaksi, dan ketangkapan dalam merespon keluhan konsumen. Beberapa atribut tersebut tidak terlalu masalah apabila tidak diperbaiki, karena atribut tersebut dianggap tidak terlalu dianggap penting oleh konsumen. Hasil penelitian ini tidak sejalan dengan Bangun dkk (2016) yang meneliti tentang sikap dan kepuasan konsumen dalam mengonsumsi ayam penyet Hang Dihi yang mendapatkan bahwa atribut yang masuk ke dalam kuadran III yaitu atribut penampilan, area parkir dan fasilitas toilet dan cuci tangan.

Variasi menu yang terlalu banyak dianggap tidak terlalu penting, karena beberapa menu saja sudah cukup bagi konsumen, seperti menu-menu tertentu yang sering dipesan konsumen dan cukup membuat rasa yang enak yang diharapkan oleh konsumen. Pada kuadran III, atribut kemudahan dalam menjangkau lokasi juga dianggap tidak terlalu penting oleh konsumen, karena lokasi Rumah Makan "XXX" Lamongan sudah cukup strategis yaitu berada di pinggir jalan raya. Kemudahan akses ke lokasi rumah makan dalam penelitian adalah kemudahan atau tidaknya lokasi tempat makan untuk dikunjungi atau dijangkau oleh banyak kendaraan. Mudahnya akses kendaraan menuju rumah makan tersebut dianggap tidak terlalu penting.

Atribut kecepatan transaksi, keramahan pelayanan, dan ketangkapan dalam merespon keluhan konsumen dianggap tidak terlalu penting oleh konsumen dan tingkat kinerjanya tidak terlalu baik. Kecepatan transaksi yang dimaksud pada penelitian ini adalah mengantri atau tidaknya dalam membayar sesudah makan, sehingga pelanggan dapat merasakan kenyamanan dan kepuasan jika dalam melakukan pembayaran dengan cepat.

Keramahan pelayan untuk setiap konsumen rumah makan selalu menyambut baik konsumen yang datang ke rumah makan dengan memberikan pelayanan yang baik bagi konsumen, sehingga konsumen tidak merasa tidak nyaman datang ke rumah makan. Namun pada kenyataannya, konsumen merasa tidak puas dengan atribut ini dikarenakan kurang ramah pelayan terhadap konsumen. Atribut ketangkapan dalam merespon keluhan konsumen yang dimaksud pada penelitian ini adalah konsumen berhak memberikan keluhan terhadap rumah makan tersebut, apabila konsumen merasa tidak puas dan nyaman terhadap rumah makan, sehingga pelanggan dapat merasakan kenyamanan dan kepuasan jika sudah memberitahu keluhannya. 


\section{Kuadran IV Berlebihan}

Atribut yang masuk dalam kuadran IV adalah penampilan produk. Atribut yang dinilai oleh konsumen tidak begitu penting, tetapi pelaksanaannya dilakukan berlebihan oleh pihak rumah makan, sehingga masuk ke dalam kategori berlebihan. Hasil penelitian ini tidak sejalan dengan Sulfiana dkk (2018) yang meneliti tentang sikap dan kepuasan konsumen terhadap paket menu lele terbang di rumah makan sambal lalap Bandar Lampung yang mendapatkan bahwa atribut yang masuk kedalam kuadran IV yaitu atribut variasi menu dan area parkir.

Penampilan produk adalah bentuk sajian yang terlihat langsung oleh konsumen. Salah satu contoh bagian dari atribut penampilan produk yang dianggap berlebihan yaitu wadah penyajian sambal dan lalapan yang disediakan. Wadah penyajian sambal menggunakan cobek batu menyebabkan pihak rumah makan menyajikan sambal dalam porsi berlebih dan jumlah lalapan yang disediakan rumah makan juga berlebih, sedangkan banyak konsumen menyisakan sambal dan lalapan, karena porsi yang disediakan berlebihan. Sebenarnya, pihak rumah makan dapat mengefisiensikan penggunaan wadah sekaligus mengurangi porsi sambal dan lalapan, sehingga dapat menekan biaya produksi.

\section{KESIMPULAN}

Hasil penelitian dapat menyimpulkan bahwa sikap konsumen untuk di Rumah Makan "XXX" Lamongan ditentukan berturut - turut antara lain: rasa masakan, harga, tingkat higienitas, dan kebersihan tempat cuci tangan dan toilet. Konsumen sudah merasa sangat puas dengan pelayanan yang diberikan oleh Rumah Makan "XXX" Lamongan dengan atribut yang harus dipertahankan kinerjanya di rumah makan tersebut yaitu cita rasa, harga, tingkat higienitas, dan kebersihan toilet dan tempat cuci tangan.

\section{DAFTAR PUSTAKA}

Bangun Y F Br, Y Indriani, dan A Soelaiman. 2017. Sikap dan kepuasan konsumen Rumah Makan Ayam Penyet Hang Dihi Bandar Lampung. JIIA, 5 (1) : 101-108. http://jurnal.fp.unila.ac.id/index.php/JIA/arti cle/view/1680/1506. [7 Maret 2019].

Dinas Pariwisata Kota Bandar Lampung. 2017. Pariwisata Dalam Angka. Dinas Pariwisata Kota Bandar Lampung. Bandar Lampung.

Doloksaribu YM, Y Indriani, dan U Kalsum. 2016. Sikap, kepuasan, dan loyalitas konsumen produk olahan bebek (Kasus di Rumah Makan Bebek Belur di Bandar Lampung). JIIA, 4 (3) : 335-341. http://jurnal.fp.unila. ac.id/index.php/JIA/article/view/1509/1363. [7 Maret 2019].

Engel JF, Blackwell RD, dan Miniard PW. 1995. Consumer Behaviour. Ed. 8. The Dryden Press.

Ghozali I. 2009. Aplikasi Analisis Multivariate dengan Program SPSS. Edisi ke-4. Universitas Diponegoro. Semarang.

Kotler P. 2005. Manajemen Pemasaran Edisi Kesebelas Jilid 1. Indeks. Jakarta.

Supranto J. 2006. Pengukuran Tingkat Kepuasan Pelanggan untuk Menaikan Pangsa Pasar. Rineka Cipta. Jakarta.

Sitorus LO. 2018. Sikap dan Kepuasan Konsumen Terhadap Pembelian Sate di Kota Bandar Lampung. Skripsi. Universitas Lampung. Lampung.

Sufren dan Y Natanael. 2013. Mahir Menggunakan SPSS Secara Otodidak. PT Elex Media Komputindo. Jakarta.

Sulfiana WN, K Murniati, dan Y Indriani. 2018. Sikap dan kepuasan konsumen terhadap paket menu lele terbang, kaitannya dengan bauran pemasaran di Rumah Makan Sambal Lalap Bandar Lampung. JIIA, 6 (1) : 72-28. http://jurnal.fp.unila.ac.id/index.php/JIA/arti cle/view/2501/2185. [9 Maret 2019]. 